\title{
Interlamellar Silylation of Montmorillonite with 3-Aminopropyltriethoxysilane
}

\author{
Kyeong-Won Park and Oh-Yun Kwon ${ }^{\star}$ \\ Department of Chemical Engineering, Iosu National Lniversitw, Yosu 550-749, Korea \\ ${ }^{\dagger}$ Department of Chemistr, Gueongsang National Lniversitw, Jin Ju 660-701, Korea \\ Received February 10, 2004
}

\begin{abstract}
H-montmorillonite was modified by interlayer surface silylation using 3-anuinopropyltriethoxysilane and dodecylamine in ethanol without a pre-swelling step. Dodecylanine acts as a gallery expander and silylation catalyst. The evaporation of ethanol from the dispersion yields well-ordered silylated nontmorillonites with large basal spacing between 1.50 and $4.20 \mathrm{~nm}$. Solid-state ${ }^{29} \mathrm{Si}$ CP MAS NMR of the silylated samples showed $\mathrm{Q}^{2}$ and $\mathrm{Q}^{3}$ signals as well as $\mathrm{T}^{2}$ and $\mathrm{T}^{3}$ signals. The increase in the relative intensity of $\mathrm{Q}^{3}$ for $\mathrm{Q}^{2}$ and the appearance of $\mathrm{T}^{2}$ and $\mathrm{T}^{3}$ signals was attributed to the grafting of 3 -aninopropy ltriethoxy silane to the interlayer surface silanol groups.
\end{abstract}

Key Words : Montmorillonite. Sily lation. Intercalation. 3-Aminopropyltriethoxy silane

\section{Introduction}

Chemical modification of silica surface is an area of intense interest from both fundamental and practical points of view ${ }^{1: 5}$ The covalent grafting of organic units on inorganic surfaces have been attempted mainly for chromatographic application. ${ }^{6}$ In recent years. the chemical modification into the interlayer surface of layered materials found increasing interests. ${ }^{7.17}$ Organochlorosilanes. used widely for the modification of silica surfaces. have also been employed for interlayer modification of layered silicates ${ }^{11.12}$ leading to covalent grafting on interfaces. The covalent grafting of ethylene glycols ${ }^{1 \hat{s}}$ and silylation of various alkylchlorosilanes ${ }^{1+16}$ into organo-layered silicates was reported

This paper reports on the grafting of 3-aminopropyltriethoxysilane in interlayer surface of acid treated montmorillonite (HMMT). The silylation mechanism of 3aminopropyltriethoxysilane into amorphous silica and alumina surface was well elucidated. ${ }^{18}$ Interlamellar sily ation of 3-aminopropyltriethoxysilane into motmorillonite was also conducted by refluxing in dry toluene. ${ }^{19}$ Our synthetic strategy was focused on the simultaneous intercalation of 3-aninopropyltriethoxysilane and dodecylamine into HMMT in ethanol without a pre-swelling step. Intercalation and silylation was easily achieved by direct evaporation of ethanol from the dispersion of HMMT in 3 aminopropyl-triethoxysilane. dodecylamine and ethanol. Attached amine groups on the surface can offer reactive sites for chemical bonds with epoxy. nylon. imide, and urethane polymers. In particular, layered materials with attached amine groups also may be used as adsorbents of heavy metal ions, supports of drugs or enzymes and photosensitive devices.

\footnotetext{
Corresponding Author. Fax: +82-61-653-3659, e-nail: oykwon àyosu.acks
}

\section{Experimental Section}

Materials. The silane coupling agent was APS [3aminopropyltriethoxy silane: $\left.\mathrm{NH}_{2}-\mathrm{CH}_{2} \mathrm{CH}_{2} \mathrm{CH}_{2} \mathrm{Si}\left(\mathrm{OC}_{2} \mathrm{H}_{3}\right)_{3}\right]$ of special grade (Adrich. USA). Dodecylamine (DDA) was used special grade (Aldrich. USA). $\mathrm{HCl}$ and $95 \%$-ethanol were used. MMT (montmorillonite) was purchased from YAGURI (Japan). The commercial MMT was purified using a sedimentation method. $2 \mathrm{wt} \%$ MMT suspension was prepared in deionized water and stirred overnight at room temperature, and then allowed to settle down for $2 \mathrm{~h}$. The sediment was removed by decantation. The purified MMT was then recovered by centrifuging the decanted upper slurry: washed and oven dried for $24 \mathrm{~h}$ at $100^{\circ} \mathrm{C}$.

HMMT was prepared by an ion exchange of exchangeable cations for $\mathrm{H}^{+}$in a $0.1 \mathrm{~N} \mathrm{HCl}$ solution. The suspension composed of purified MMT $(40 \mathrm{~g})$ and deionized water $(500$ $\mathrm{mL}$ ) was slowly titrated with a $0.1 \mathrm{~N} \mathrm{HCl}$ solution to a final $\mathrm{pH}$ of 1.8 and then maintained at the same $\mathrm{pH}$ value for an additional $24 \mathrm{~h}$. The sample was recovered by filtering. washed with deionized water to be $\mathrm{Cl}$-free, and then dried in air for $24 \mathrm{~h}$ at $100^{\circ} \mathrm{C}$. The replacement of exchangeable cations by $\mathrm{H}^{-}$in the layered silicate produces organophilic properties in the interlayer surfaces because the silanol groups produce hydrogen-bonding sites

Sample preparation. APS solutions were prepared to be $0.01 \mathrm{M}-0.1 \mathrm{M}$ in ethanol $(95 \%)$. HMMT $(1.0 \mathrm{~g})$ was dispersed in $10 \mathrm{~mL}$ of these solutions (ultrasound for 20 $\mathrm{min}$ ) at room temperature. The dispersion was evaporated to dryness for $24 \mathrm{~h}$ at $50^{\circ} \mathrm{C}$ (APS-MMT). To investigate swelling property of APS-MMT, $1.0 \mathrm{~g}$ samples were dispersed in $0.5 \mathrm{M}$ DDA-ethanol solution $(10 \mathrm{~mL})$ and dried by evaporating for 24 h at $50^{\circ} \mathrm{C}$ (APS-MMT-DDA).

DDA-APS mixed solutions was also prepared by dissolving APS and DDA in ethanol $(95 \%)$. The concentrations of APS in solution was $0.01 \mathrm{M}-0.1 \mathrm{M}$. concentration of DDA was $0.1 \mathrm{M}-0.5 \mathrm{M}$. HMMT $(1.0 \mathrm{~g})$ was then dispersed in 10 $\mathrm{mL}$ of these solutions (ultrasound, $20 \mathrm{minl}$. at room 
temperature) and evaporated to dryness for $24 \mathrm{~h}$ at $50{ }^{\circ} \mathrm{C}$ (DDA-APS-MMT).

Characterization. Powder $\mathrm{X}$-ray diffraction measurements were recorded on a Rigaku Rotaflex $200 \mathrm{~B}$ diffractometer equipped with CuK $\alpha \mathrm{X}$-ray radiation and a curved crystal graphite monochromator. Solid-state ${ }^{29}$ Si MAS NMR spectra were recorded on a Bruker CXP-100 spectrometer at a resonance frequency of $19.89 \mathrm{MHz}$. with a $45^{\circ}$ pulse and a recycle delay of $7 \mathrm{~s}$. Fnergy dispersive X-ray spectrometer analysis (ГDS, Link system AS1000-85S) and thermo gravimetric analysis (TGA, $10^{\circ} \mathrm{C} / \mathrm{min}$ to $900^{\circ} \mathrm{C}, 100 \mathrm{cc} / \mathrm{min}$ $\mathrm{N}_{2}$ purge) were performed.

\section{Results and Discussion}

The X-ray powder diffraction pattern of purified MMT exhibits several (001) reflections, indicating a basal spacing of $1.51 \mathrm{~nm}$ (Figure 1a). This is larger than that $(1.23 \mathrm{~nm})$ of commercial MMT. It is attributed to solvation of interlayer cations by water molecules. Gillery ${ }^{20}$ reported that the basal spacing of clay minerals is closely related to the relative humidity. Air-dried HMMT is very similar to MMT except for a little decrease in basal spacing (Figure 1b). This indicates that the original structure of MMT dose not change by the acid treatment. Decrease in the basal spacing indicates a loss of the interlayer $\mathrm{H}_{2} \mathrm{O}$ upon the replacement of exchangeable cations for $\mathrm{H}^{+}$. Analysis of EDS showed that the intrinsic $\mathrm{Na}$ and $\mathrm{K}$ peak in purified MMT disappeared in HMMT. This proves that the acid treatment of MMT results in complete exchange of exchangeable cations for $\mathrm{H}^{-}$.

Figure 2 shows the XRD patterns for HMMT treated with $0.01,0.05$ and $0.1 \mathrm{M}$ APS-ethanol solutions. During this process, the APS molecules were intercalated and grafted to interlayer surface silanol groups. The basal spacing of the APS-MMT increases $1.52 \mathrm{~nm}$ to $1.89 \mathrm{~nm}$ with increased

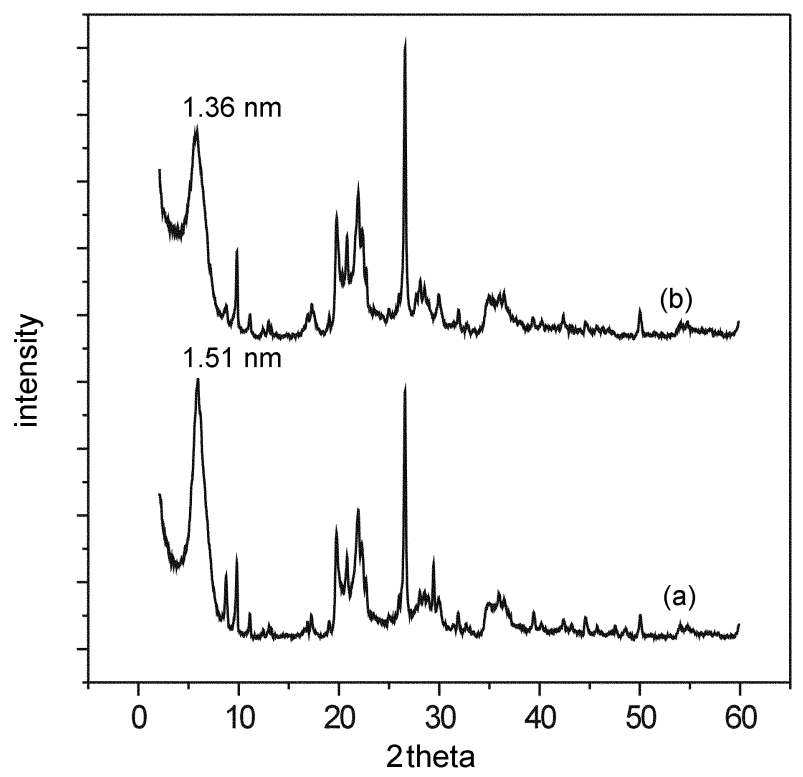

Figure 1. XRD pattern of (a) purified MMT and (b) HMMT.

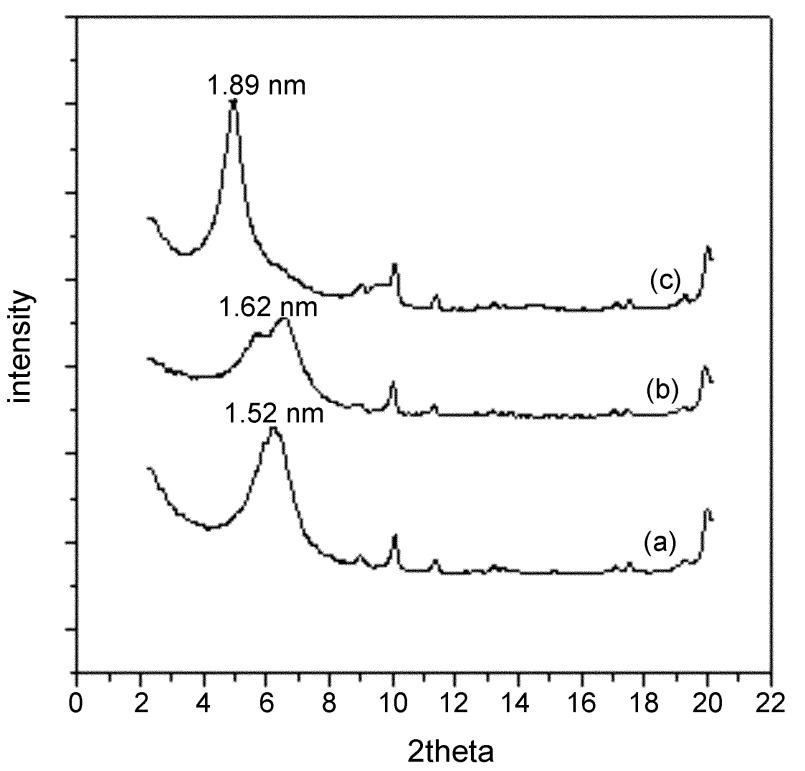

Figure 2. XRD patterns of [IMMT treated with $\mathrm{APS}$-ethano] solution. (a) 0.01APS-MMT. (b) 0.05APS-MMT and (c) 0.1 APSM.MT.

APS concentration, allowing large expansion (from $0.11 \mathrm{~nm}$ to $0.53 \mathrm{~nm}$ ) of interlayer space. This indicates that the APS molecules arrange in monolayers or paraffin-type between the aluminosilicate layers. The interlayer space, at lower concentration $(0.01 \mathrm{M}$ and $0.05 \mathrm{M})$, cannot intercalate enough to fill with APS molecules, resulting in only monolayer or double layer arrangement. In case of this, APS can build a bridge between adjacent layers by silylating with silanol groups in adjacent interlayer surface (interlayer condensation). This interlayer condensation may lose swelling property of APS-MMT. However, at higher concentration $(0.1 \mathrm{M})$, the interlayer space expends to molecular length $(\sim 0.7 \mathrm{~nm})$ of APS because APS molecules fill with enough to allow paraffin-type. This shows that APS graftedMMJ with large basal spacing can be prepared simply by evaporation of solvent from the dispersion of HMM' in APS-ethanol solution. In general, grafting of Al'S on the silica surface was conducted by filtering after reaction for several hours in toluene comprising excess APS.

Figure 3 shows the swelling property of APS-MMT in 0.5 M DDA-ethanol solution. HMM' in DDA-ethanol solution showed large increase of the basal spacing to $4.6 \mathrm{~nm}$ after drying. This indicates that DDA molecules are arranged in a bilayer structure. APS-MM' $(0.01 \mathrm{M})$ showed excellent swelling properties in DDA, resulting in well ordered intercalates with a basal spacing of $4.2 \mathrm{~nm}$. Swelling by DDA of APS-MM'l implies that interlayer condensation does not happen between adjacent interlayer surfaces. However, increasing concentration of APS (0.05 and 0.1 M) broadens the reflections and decreases the basal spacing because a higher degree of grafting reduces the amount of intercalated DDA.

The treatment of HMM I with APS-DDA mixed solution ensures successful silylation of APS. The dried powders 


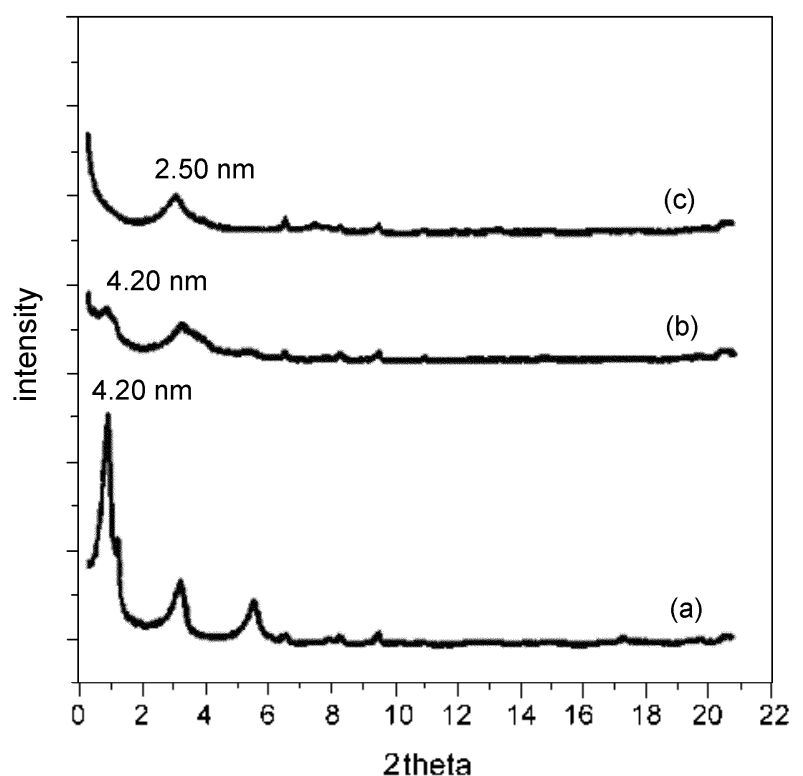

Figure 3. XRI patlerns of APS-MMT treated will $0.5 \mathrm{~V}$ DDAethand solution. (a) 0,01 $\mathrm{APS}-\mathrm{MMT}$, (b) $0.05 \wedge \mathrm{PS}-\mathrm{MMI}$ and (c) 0.IAPS-MMT:

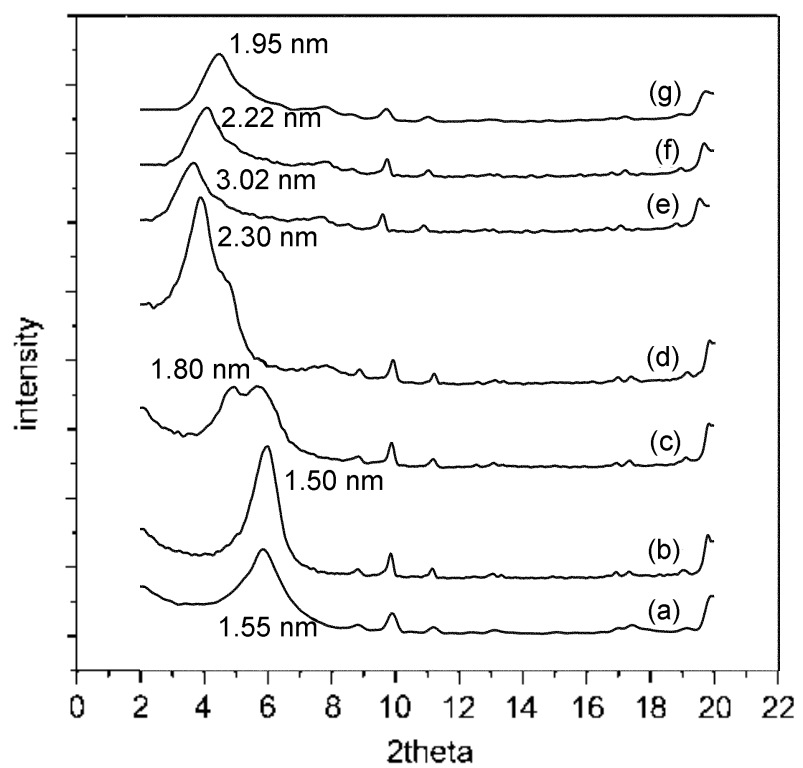

Figure 4. XRD patterns of HMMT treated simultancously with APS and DDA in ethanol. (a) 0.01DDA-0.01APS-MMT. (b) 0.05I)I A-0.05APS-MMT. (c) 0.1IIIN-0.IAPS-MMT: (d) $0.3 \mathrm{DD} \wedge-0.01 \wedge \mathrm{PS}-\mathrm{MMT}$ (e) 0.5DDA-0.0I APS-MMT (t) 0.5DDA0.05 APS-MMT. and (g) 0.5DDA-0.1APS-MMT.

consist of HMMT with intercalated APS and DDA. Figure 4 shows that the basal spacing of DDA-APS-MM'T samples exhibits large difference of $1.55 \mathrm{nun}$ to $3.02 \mathrm{~nm}$, depending upon concentration of DDA and APS. Increasing concentration of DDA results in large increase in basal spacing ( $\mathrm{a}, \mathrm{d}$ and $e ; b$ and $f$. In particular, the intercalation of DDA is influenced by co-intercalate APS ( $e, f$ and $g$ ). More ordered and larger basal spacing (e) result from the sample (0.5DDA-0.01APS) prepared in solution with the largest

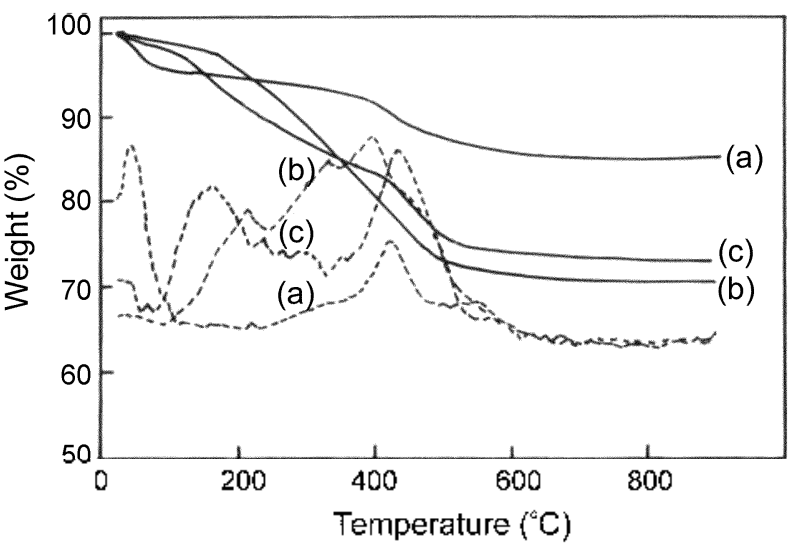

Figure 5. The thermogravimetric analysis of (a) 0.1 APS-MMT, (b) $0.5 \mathrm{I}) \mathrm{I}) \mathrm{A}-\mathrm{MMT}_{\mathrm{N}}$ and (c) $\left.\left.0.5 \mathrm{I}\right) \mathrm{I}\right) \wedge-(0.1 \wedge \mathrm{PS}-\mathrm{MMT}$ :

difference in relative concentration of DDA and APS. However, increasing concentration of APS ( $\mathrm{c}, \mathrm{g})$ broadens the reflections and decreases the basal spacing because a higher degree of grafting reduces the amount of intercalated DDA.

The TGA data obtained from 0.5DDA-MMT, 0.1APSMMT and 0.5DDA-0.1APS-MMT are illustrated in Figure 5. 0.5DDA-MMT appears weight losses at broad range between $100^{\circ} \mathrm{C}$ and $500^{\circ} \mathrm{C}$, caused by desorption and combustion of intercalated DDA. However, APS graftedMMT exhibits two-step weight loss. The weight loss below $100{ }^{\circ} \mathrm{C}$, in 0.1 APS-MMT, is from desorption of ethanol molecules and the loss occurring atter $400^{\circ} \mathrm{C}$ is from combustion of the silylated APS. Two-step weight loss, in 0.5DDA-0.1APS-MMT, is attributed to different bonding environment of DDA and APS in the gallery. The initial weight loss below $200^{\circ} \mathrm{C}$ is from desorption of nonintercalated or intercalated DDA molecules and loss after $400^{\circ} \mathrm{C}$ is from combustion of the silylated APS.

The solid-state ${ }^{21} \mathrm{Si}$ CP MAS NMR spectra for silylated HMMT show $Q^{2}(-90 \mathrm{ppm}), \mathrm{Q}^{3}(\cdots-96 \mathrm{ppm}), \mathrm{T}^{2}(-50 \mathrm{ppm})$ and $T^{3}(\cdots-60 \mathrm{ppm})$ signals due to diverse environments of silicon (Figure 6). In general. MMT exhibits a resonance in the range from -75 to $-95 \mathrm{ppm}$, which are typical of several additional silicon environments. ${ }^{21,22}$ Each $\mathrm{Si}$ atoms in $\mathrm{SiO}_{+}$ structures have two or three $\mathrm{Si}$ atoms as nearest neighbors $\left(Q^{2}, Q^{3}\right)$ and remaining nearest neighboring atom/atoms being either $\mathrm{Al}$ or $\mathrm{H} . \mathrm{Q}^{2}$ is attributed to central $\mathrm{Si}$ in

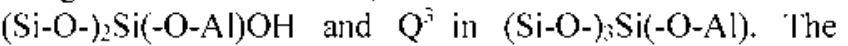
increase of $\mathrm{Q}^{3} / \mathrm{Q}^{2}$ ratio compared with $\mathrm{HMMT}$ clearly indicates the grafting of APS molecules to surface silanol groups. New peaks $\left(\mathrm{T}^{-2}\right.$ and $\left.\mathrm{I}^{3}\right)$, near -50 to $-60 \mathrm{ppm}$, in $0.3 \mathrm{DDA}-0.01 \mathrm{Al} S-\mathrm{MMT}$ are attributed to the $\mathrm{Si}$ atoms of the grafted APS molecules. The Si signals for APS silylated on silica appeared in the range of $-49 \mathrm{ppm}$ to $-68 \mathrm{ppm}$ depending upon bonding type..$^{2.3} \mathrm{Si}$ signals for alkyltrichlorosilane grafted on layered silicates was also appeared at $\sim-56$ to $-65 \mathrm{ppm} .{ }^{16.17}$ Here, all the APS molecules may not silylate with silicate surface because APS could hydrolyze in water. 


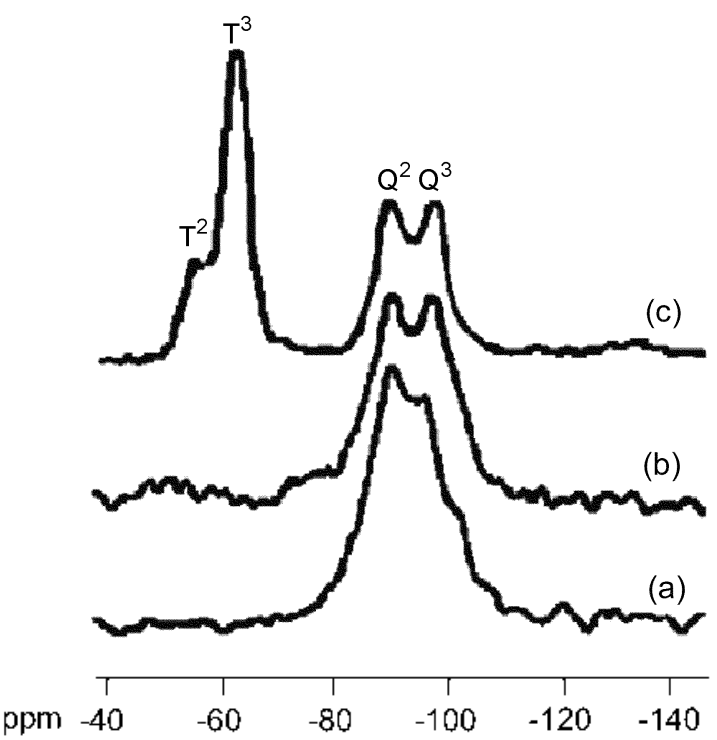

Figure 6. ${ }^{39} \mathrm{Si}$ CP MAS NMR spectra of (a) HMMT. (b) 0.I APSMMT and (c) 0.3DDA-0.01APS-MMT.

Above results show that the silylation by APS and intercalation of DDA proceeded more effectively by evaporation of the solvent from the dispersion of HMMT, APS, DDA and ethanol. Amine groups of APS and DDA molecules are very accessible to silanol groups in interlayer surface. Solvent also solvates interlayer $\mathrm{Si}-\mathrm{OH}$ groups and makes easy intercalation of DDA and APS into interlayer. The solvation of DDA and APS within gallery results in additional expansion in gallery. DDA and APS molecules in gallery can have fully stretched arrangement. Evaporation of ethanol starts at the outside of particle, resulting in a higher concentration of DDA and APS on the external surface. This promotes intercalation of APS and DDA. The evaporation of residual ethanol in the gallery results in silylation of APS. The water molecules contained in ethanol catalyze interlayer surface silylation of APS during the evaporation of ethanol. The condensation of alkoxysilane is known to catalyze by base. DDA as gallery expander can also have a role as catalyst for the grafting of APS into the surface silanol groups. This evaporation process should be very efficient method for intercalation and silylation of silane coupling agents into layered materials and mesoporous materials.

\section{Conclusions}

MMT with attached amine group in interlayer surface was prepared successfully. The process proceeded more effectively by evaporation of the solvent from the dispersion of HMMT, APS, IDIDA and ethanol. APS was intercalated directly into interlayer space of acid-treated MMT and silylated with interlayer silanol groups, resulting in the grafting of APS on interlayer surfaces. DDA could have a role as gallery expander or silylation catalyst. Tthanol could control quantitatively the amount of APS and DDA needed to the gallery silylation and the water contained in ethanol catalyze interlayer surface silylation.

\section{Reference}

1. Plucddemann. F. P. Silone Coupling Agents: Ploenum: New York. 1982.

2. Sung. C. S. 1.: Lee. S. H.: Sung. N. H. Polym. Sci. Technol, 1980. I2B. 757.

3. Kulkarni. R. D.: Goodard. E. D. Int I. Adhes. theses. 1980. I. 73.

4. Furukawa. T.: Fib. N. K.: Mittal, K, I.: Anderson, I, R. f. Colloid Inerfoce So. 1983. 96. 322.

5. Alexander. J. D.: Gent. A. V.: Henriksen. P. N. J. Chem. Phys 1985. 83.5981.

6. Pesck. I. J. In Chemically Wodiffed Oxide Surfaces: Leyden. D. F... Collins. W. T., F.ds.: Gordon \& Bruach: New York. L. S. A. 1990: Vol. 3. p 93.

7. Kwon. O. Y.: Park. K. W. Bull Norean Chem Soc, 2003, 24. 1561 .

8. Kwon. O. Y.: lark. K. W. Bull. Korean Chem. Soe 2004. 25. 25.

9. Kim, J, W, I iu. F.: Choi, II, J. J. Ind the Chem. 2002, 8. 399.

10. Kwon. O. Y: Park. K. W.J. hid. Eng. (hem. 2004, 10, 252.

1 1. Ruiz-l ditzk, I:.. Rojo. J. M. Nature 1981. 287. 28.

12. Ruiz-Hitzky. E.: Rojo. J. M.: Lagaly. G. Colloid Polym. Sci. 1985. 263. 1025 .

13. Tunn: I. M.: Detellier. C. ('hem. Hetter: 1993. 5. 747.

14. Ogawa. M.: Okutomo. S.: Kurodia K. . . Am. Chem. Soc. 1998. 120. 7361

15. Isodil K.: Kuroda. K.: Ogawa W. Chent. Hater 20001. I2. 1702 .

16. Shimojima. A.: Mochizuki. D.: Kuroda. K. Chem. Hater 2001. 13. 3603 .

17. Thiesen, P. H.: Bennekt, K.: I agaly. G. J. Hater Chem. 2002, /2. 3010 .

18. Impens. N. R. I:. N.: Vort. V. P.: Vansant. I. I: Mficroporous and Mesoporots Later 1999. 28. 217.

19. Mukkanti. K.: Subba Rao. Y. V.: Choudary. B. M. Tetwhedron Letters 1989. 37. 251 .

20. Gillery, F, II. Am. Wineralog. 1959. 44, 806.

21. Thompson, A, R.: Botto. R, E. Energy \& Fitels 2001. /5, 176.

22. Carrado. K. A.: Xu. L.: (Gregon: D). M.: Song. K.: Seilert. S.: Botto. R. E. Chen Water 2000. I2.3052.

23. Caravajal. G. S.: Leyden. D. E.: Quinting. G. R.: Maciel. G. E. Andt ('h'm. 1988. 60). 1776. 